\title{
Feminismo, maternidade e mídia: relações historicamente estreitas em revisão
}

Renata Tomaz

Resumo: Partindo do princípio de que a maternidade é uma construção social cada vez mais vinculada aos processos comunicacionais, sobretudo na voluptuosa oferta de conselhos e diretrizes do que é ser mãe, este trabalho procura situar tal debate com base nas principais abordagens feitas sobre maternidade nos estudos feministas. O trabalho apresenta um recorte do estado dessa pesquisa no Brasil, chamando atenção para três eixos temático-teóricos e para os possíveis pontos de exploração nos estudos de mídia e maternidade.

Palavras-chave: mídia e maternidade; feminismo; gênero; revisão de literatura.

Abstract: Feminism, motherhood and the media - historically close relations in review - We start from the premise that motherhood is a social construct increasingly linked to communication processes, especially in the voluptuous offer of advice and guidelines of what is to be a mother. Taking on from this idea, this paper seeks to situate such debate. Based on the main approaches about motherhood in feminist studies, the paper presents a state-focused approach of this research in Brazil, bringing attention to three thematic-theoretical axes and to potential topics yet to be explored in media and motherhood studies.

Keywords: media and motherhood; feminism; gender; literature review.

É cada vez mais indissociável a relação entre mídia e maternidade. A voluptuosa oferta de produtos de informação voltados para a criação de filhos sinaliza os processos comunicacionais como espaço privilegiado de prescrição dos procedimentos necessários para o exercício adequado da maternagem. Programas de rádio e TV, blogs, redes sociais, portais de conteúdo especializado, revistas, colunas em jornais e manuais são exemplos fartos dessa percepção. Levando-se em conta que a mídia é um local inegável de produção de sentido, a comunicação tornou-se um espaço singular para a pesquisa das mais diferentes áreas do conhecimento interessadas na construção social da maternidade. 
A pesquisa a que este artigo se vincula investiga as narrativas midiáticas que constroem as diferentes possibilidades da infância no contexto brasileiro - uma experiência inegavelmente atravessada, dentre outros aspectos, pelos ideais de maternidade circulantes. Por essa razão, é fundamental conhecer os principais aportes teóricos desenvolvidos e utilizados nesse contexto para compreender quê mãe, ou seja, quê figura feminina é essa que afeta a experiência da infância no contemporâneo.

A metodologia utilizada neste trabalho partiu de uma busca com as palavras "mídia maternidade" no Portal de Periódicos da Capes, no Google Acadêmico e no RCAAP (Repositório Científico de Acesso Aberto de Portugal). Foram listados mais de oitenta textos entre artigos, papers, dissertações e teses publicados, apresentados ou defendidos, nos últimos dez anos (2003-2013), no Brasil. Eles foram organizados por título, autoria, universidade de origem, tipo de texto (artigo, tese, dissertação, etc.), área do conhecimento e palavras-chave.

$\mathrm{Na}$ segunda fase, foi realizada uma leitura que privilegiou, além do título, das palavras-chave e dos resumos, a introdução e a conclusão dos textos em língua portuguesa e, em alguns casos, quase a totalidade do material. Dentre as perguntas a que busquei responder estão: Qual abordagem foi dada à relação mídia e maternidade? Qual o argumento central do trabalho? Que quadro teórico foi utilizado? Que veículos de comunicação foram analisados? Nessa fase, os textos foram lidos dos mais recentes para os menos recentes - o que ajudou bastante na hora em que eram encontrados textos que se referiam a fases diferentes de uma mesma pesquisa.

Além disso, a partir desse material, foram listadas cerca de vinte novas referências de artigos e livros citados nos textos lidos - compreendidos, nesse sentido, como material de referência no assunto. Essa leitura foi feita em uma terceira fase. Sendo assim, os dados encontrados nesse levantamento foram utilizados para situar a pesquisa sobre a temática maternidade e mídia e seu desenvolvimento no Brasil.

Com eles, foi possível pensar a produção nacional a partir de três eixos temáticoteóricos, que podem constituir pontos de exploração nos estudos de mídia e maternidade, na esfera das ciências sociais, especialmente na comunicação. Antes da análise, entretanto, vale situar a temática no âmbito dos estudos feminista e, em seguida, mostrar a estreita relação existente entre a mídia brasileira e a construção de ideais de maternidade.

\section{Maternidade na perspectiva feminista}

Como será mostrado, os aparatos de mídia no Brasil ocupam historicamente uma posição de destaque na constituição do que é ser mãe. Tal afirmação se estriba no entendimento de que, apesar de a maternidade ser uma condição biológica exclusiva da mulher, ela também é uma condição social. Isto é, embora a gestação, o parto e a amamentação sejam possibilidades restritas ao corpo dela, é no âmbito da cultura e de uma dada configuração histórica que a mulher vai lidar com cada uma dessas fases 
- as experiências de engravidar, dar à luz e amamentar estão alinhadas com as relações sociais estabelecidas e vigentes. Essa compreensão é tributária dos movimentos e estudos feministas, sobretudo em meados do século XX. Eles tornaram possível uma concepção social e não apenas biológica do feminino, permitindo conceber a maternidade para além da ideia de um destino inescapável da mulher.

Especialmente nos anos 1960, a maternidade passa a ser vista como uma condição biológica utilizada socialmente para restringir a mulher ao espaço doméstico e, nesse sentido, oprimi-la. Essa ideia perpassava obras como A mística feminina (1971[1963]), da socióloga feminista Betty Friedan. O trabalho de Badinter (1985), embora publicado anos depois, tem um diálogo direto com essa discussão. A filósofa francesa afirma que, embora a palavra instinto tenha sido extirpada como chave explicativa para o comportamento humano, no caso da maternidade sua ideia permanece na concepção de amor materno. Ela recusa toda ideia de amor inato, isto é, que não seja construído no interior de uma relação completamente pessoal e engendrado numa dinâmica social específica.

Nos anos 1970, sobretudo pela influência da psicanálise, tanto os movimentos quanto os estudos feministas repensaram a maternidade, que começa a ser entendida como um diferencial. Chodorow (1978) defendeu, por exemplo, que a maternidade é reproduzida ciclicamente em bases biológicas, sociais e, especialmente, psicológicas, numa construção subjetiva. Ser mãe, nesse sentido, não significaria necessariamente perder a individualidade.

Dos anos 1990 em diante, pode-se dizer, ganham maior alcance trabalhos como o de Butler (1990) que, sob a influência predominante de Foucault, questiona as instâncias tradicionais de poder e desloca seu olhar para as microrrelações e, particularmente, para corpo da mulher. Nesse sentido, as investigações não se limitam às questões ideológicas, mas avançam para uma preocupação com a subjetividade feminina. A tendência a um feminismo mais centrado na mulher-sujeito do que nas questões igualitárias que calibraram os estudos feministas dos anos 1960 e 1970 se reflete diretamente nos trabalhos que analisam a maternidade (TUTTLE, 1997; SCAVONE, 2001, 2004b; STEVENS, 2013).

O que se pode depreender desses três momentos é que, embora a diferença biológica tenha sido, de certa forma, um ponto de partida para os estudos feministas analisarem a maternidade, houve uma compreensão de que as disputas de poder não podem ser pensadas apenas desse ponto de vista, mas de uma perspectiva social. Afinal, o problema não está no corpo da mulher ou do homem, mas nos sentidos socialmente construídos e atribuídos a tais diferenças e a suas possibilidades e potencialidades. Sendo assim, a maternidade, com tais contribuições, foi desnaturalizada e passou a ser compreendida como um papel social atribuído à mulher dentro de uma organização sexual do trabalho.

\section{Maternidade e mídia no Brasil: a construção da mãe moderna}

No final do século XIX, o Brasil já contava com diferentes periódicos que se propunham a "educar a mãe", slogan do jornal $A$ Família, editado em São Paulo entre 
os anos 1888 e 1894. Sua proposta era similar ao jornal A Mãi de Familia, produzido no Rio de Janeiro entre os anos 1879 e 1888. A expressão "educação da mãe" se tornou corriqueira nessa época, quando a mulher brasileira burguesa foi convocada pela sociedade para educar o futuro cidadão da República. A mãe que se procurava não deveria ser mais aquela formada nos conselhos e diretrizes das mulheres mais velhas, mas nas orientações dos homens da ciência (SCAVONE, 2004a; FREIRE, 2008; MARTINS, 2008).

Nesse momento, os periódicos e os manuais foram ferramentas fundamentais na disseminação das ideias que iriam construir o imaginário da mãe moderna - forjada não mais na sabedoria das avós, sogras, comadres, vizinhas, parteiras e curandeiras, mas no domínio da ciência, mais especificamente, dos homens da ciência.

Freire (2008) estudou a importância das revistas femininas no início do século XX, analisando as revistas Vida Doméstica e Feminina, que circularam no Rio de Janeiro nos anos 1920. Ela defende que essa alteração de uma maternidade construída em bases tradicionais para uma de base científica não pode ser vista apenas como uma dominação masculina. Para ela, a mudança, que congregou médicos, juristas, educadores e feministas, conferiu visibilidade à figura da mãe e permitiu que o papel social da mulher, incluindo a maternidade, ocupasse o espaço público.

Ao pesquisar três manuais publicados na primeira metade do século XX, Martins (2008) investiga as raízes de uma demanda por conselhos de especialistas, na maioria das vezes médicos. É curioso que o primeiro manual analisado, Vamos criar seu filho (1938), de Carlos Prado, seja resultado, nas palavras dele, "de seu trabalho na imprensa periódica desde 1925, respondendo cartas que eram enviadas para a seção de higiene infantil do Diário Nacional e a seção 'Palavras às mães' do Diário de S. Paulo" (PRADO, 1938 apud MARTINS, 2008, p. 147).

Em Cartilha às mães (1935), de José Martinho da Rocha, e A vida do bebê (1941), de Rinaldo De Lamare - este último comercializado até hoje - os pediatras usam a ideia da mãe-enfermeira, aquela que observa em tudo a criança e se reporta ao médico sem intervir na situação, mas aguardando seu direcionamento. É preciso lembrar que essa mãe especificamente é de uma classe abastada. Isso Ihe permite pagar por tais serviços, consumir essa literatura e compreender uma determinada linguagem em um projeto de distinção social. Permite, ainda, dedicar-se à tarefa exclusiva de ser mãe, diferentemente das mães trabalhadoras ou das escravas.

A tríade especialista, mãe e mídia lançava as novas bases sociais da maternidade. Os processos de comunicação se tornavam cada vez mais importantes na transferência gradativa do aprendizado da maternagem - de um ambiente doméstico, familiar, tradicional e feminino para um ambiente público, midiático, científico e masculino.

Em 1968, foi lançada no Brasil a revista Pais e Filhos, com circulação nacional até hoje. O slogan da época, "A revista da família moderna", apontava para sua principal proposta: oferecer às mulheres informações e diretrizes para a criação de filhos de 0 a 18 anos, baseadas no conselho e no conhecimento de especialistas, sobretudo do campo psicológico. 
Atualmente, um verdadeiro exército formado por pediatras, psicólogos, psicopedagogos, neuropediatras e nutricionistas, entre outros, ocupa os territórios midiáticos por meio de produtos que alimentam cotidianamente o imaginário social da maternidade. A mídia, portanto, foi de fundamental importância para trazer ao espaço público as questões privadas da mulher, dentre as quais se destaca aqui a da condição de mãe.

\section{Maternidade e mídia: estudos brasileiros recentes}

Levando-se em conta que a maternidade é um elemento constitutivo das identidades femininas, a temática apareceu em boa parte dos trabalhos produzidos no Brasil, nos últimos dez anos, não como um assunto central, mas como algo fundamental nas discussões, sobretudo, de gênero. A escolha da mídia como um lugar privilegiado de estudo das questões da maternidade não pode ser vista como uma opção que atende, por exemplo, às exigências do campo da comunicação. Trata-se de um reconhecimento, por parte de diferentes áreas, de que as práticas comunicacionais são cada vez mais constitutivas dos ideários da maternidade.

Isso pode ser visto nos textos analisados, originários de oito diferentes áreas do conhecimento: educação, comunicação, psicologia, saúde, ciências sociais e políticas, antropologia, história e letras - disciplinas que, ao pesquisar a maternidade segundo questões próprias, definem diferentes produtos midiáticos como corpus de pesquisa. A educação constitui o campo que, no Brasil, mais produziu material sobre o assunto, principalmente na região Sul que, ao lado da região Sudeste, concentra a maior parte dos trabalhos e periódicos voltados para os estudos de gênero, embora tenha sido produzido material em todo o país.

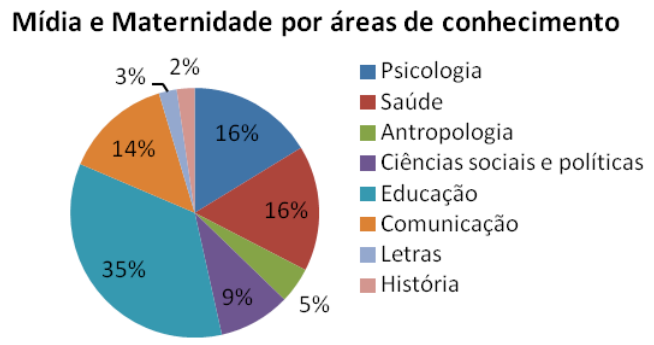

Fig. 1. Áreas de onde se originaram os trabalhos sobre mídia e maternidade, produzidos entre 2003 e 2013 , no Brasil.

Todos os trabalhos analisados, com exceção de um, apresentam pesquisas empíricas, a partir das quais foram investigadas mídias impressas, eletrônicas e digitais. Foram encontrados no levantamento, como objeto de estudo, produtos midiáticos de 
natureza digital, impressa e eletrônica. O veículo mais utilizado nas análises foi Pais e Filhos, e a ferramenta a que mais se recorreu foi a análise de discurso. Apenas dois textos escritos por homens foram encontrados. Todos os demais eram de mulheres.

Com o objetivo de organizar tamanho material, os trabalhos foram dispostos em três eixos temático-teóricos. Obviamente, essa categorização não dá conta de todas as especificidades nas análises realizadas. Mas ajuda a pensar de maneira mais ampla as principais temáticas e abordagens teóricas que estão sendo utilizadas pelos investigadores brasileiros.

O primeiro é o que coloca em tensão as representações do feminino na mídia brasileira, dentre as quais se insere com bastante força a de mãe. É perceptível uma tendência em desnaturalizar o imaginário da maternidade nas sociedades. Nos textos prevalecem abordagens segundo as quais a mulher, embora sendo retratada de forma diferente (independente, inserida na política ou consumidora dos serviços que oferecem novas tecnologias de reprodução), ainda é naturalizada na condição de mãe, por meio de ideias como sua maior responsabilidade em cuidar dos filhos ou uma suposta habilidade inata para o exercício da maternagem.

Os estudos analisados, que se encontram nessa categoria, resistem à "redução da identidade feminina ao exercício da maternidade" (ESCOSTEGUY; BARBOSA, 2011, p. 459). Nesse enfoque, são recorrentes chaves explicativas forjadas no âmbito dos estudos culturais e dos estudos feministas. O gênero, a despeito de suas diferentes possibilidades de interpretação, é um conceito central em tais discussões, visto que permite entender a maternidade para além de um dado biológico, universal, mas como um papel constituinte da figura feminina.

Dentre os autores comumente citados para referenciar essa abordagem, destacam-se Scott (1991), Hall (2006) e Silva (2009). A professora do Programa de Pós-Graduação em Comunicação da PUC-RS, Ana Carolina Escosteguy, é uma das principais referências brasileiras nos estudos de gênero. Ela pesquisa o tema, tanto no âmbito da graduação quanto da pós, desde os anos 1980/1990, orientando monografias, projetos de iniciação científica, dissertações e teses sobre a referida temática. Seu interesse está nas "diferenças históricas estabelecidas entre homens e mulheres na vida social, em especial no Ocidente Moderno" (ESCOSTEGUY, 2008, p. 6). Embora a maternidade não seja central em seu trabalho, ela aparece constantemente como parte constitutiva (muitas vezes indissociável) da identidade feminina.

Um segundo eixo estaria preocupado em problematizar o investimento no corpo da mulher a partir de sua capacidade biológica de gestar uma criança. São análises que investigam, por exemplo, os corpos grávidos e a formulação de políticas e programas públicos voltados para a manutenção do corpo da mulher. Dentre os trabalhos, podese destacar o de Rezende (2011), da UERJ, que analisa as edições de 2007 da Revista da Gestante, abordando uma gestação naturalmente emotiva. Tais sentimentos, especialmente de ansiedade e medo, dialogariam diretamente com os modos pelos quais os sujeitos se constituem na contemporaneidade, especialmente as mães, que passariam a experimentar novos processos de subjetivação. 
Uma autora brasileira que se destaca nessa categoria é Dagmar Meyer, do Programa de Pós-graduação de Educação da UFRGS. Ela já vem há alguns anos pesquisando a constituição das políticas públicas em relação à questão do gênero, razão pela qual desenvolveu o conceito de politização da maternidade (MEYER, 2003, 2006; SCHWENGBER, MEYER, 2011), cunhado a partir de uma historicização dos cuidados sobre o corpo da mulher. A ideia de tratá-lo vincula-se a uma preocupação com a criança, ainda na barriga.

Nesse sentido, uma série de políticas públicas vigentes tende a atender às necessidades da mulher que é mãe, privilegiando sua capacidade reprodutiva, embora ela exerça atualmente uma série de outros papeis. Sobressaem-se, para tais análises, os autores pós-estruturalistas, especialmente Foucault $(1988,1989)$. Sua perspectiva permite, por exemplo, pensar o exercício do poder sobre as mulheres não por parte apenas do Estado, mas a partir das microrrelações. O escrutínio do corpo feminino possibilita uma produção de saberes por meio dos quais o poder pode perpassar em diferentes práticas sociais.

Um terceiro eixo pode ser organizado em torno da compreensão da mídia como um espaço de pedagogia com autoridade proveniente, sobretudo, dos especialistas para ensinar às mulheres a tarefa de ser mãe. Em sua dissertação de mestrado, defendida em 2010, Eliane Cadoná (PUC-RS) investiga as prescrições do que é ser uma boa mãe na contemporaneidade, por meio de uma análise das campanhas de amamentação da Sociedade Brasileira de Pediatria, apontando para o que se poderia chamar de uma pedagogia da maternagem.

Em boa parte dos textos observados, tal análise se utiliza de uma combinação de abordagens teóricas. Os estudos culturais são utilizados especialmente para a compreensão dos meios de comunicação como produtos culturais, enquanto os estudos de gênero situam as narrativas da maternidade em uma configuração social da condição de mãe.

A perspectiva pós-estruturalista, por sua vez, é bastante acionada para pensar as linhas de poder que perpassam as relações sociais estabelecidas a partir das práticas comunicacionais apresentadas. Nesse sentido, a mídia é pensada a partir das relações saber-poder, por meio das quais é entendida como um espaço capaz de ensinar. Esse é basicamente o enfoque do trabalho de Maria Simone Schwengber, também do Programa de Pós-graduação em Educação da UFRGS. Ela defende o papel da mídia, especialmente a impressa, como um produto cultural pedagógico do qual se faz uso cada vez mais frequente em detrimento dos antigos conselhos familiares e que prioriza o discurso científico, ancorado no conhecimento dos especialistas, entendido como verdade (SCHWENGBER, 2009; SCHWENGBER, MEYER, 2011). Alinhados a essa compreensão estão conceitos e ideias como os de "dispositivo pedagógico da mídia" (FISCHER, 2001), "dispositivo da maternidade" (MARCELLO, 2005) e "poder informacional" (SCHWENGBER, 2012).

É preciso pontuar nessa categorização que, embora cada temática esteja associada a um aporte teórico específico, os estudos culturais, os estudos de gênero, os estudos feministas e os pós-estruturalistas estão presentes de uma forma ampla nos textos 
observados e analisados para este levantamento. A classificação, como dito anteriormente, é uma tentativa de organizar preliminarmente a produção brasileira dos últimos dez anos sobre a temática maternidade e mídia.

É importante ressaltar, ainda, que esses eixos temático-teóricos dialogam com a estreita relação histórica entre mídia e maternidade - uma relação que nasce de um esforço da sociedade brasileira em educar a mulher para se tornar uma mãe moderna, não só por meio de orientações sobre os cuidados com o bebê, mas especialmente através de diretrizes a respeito do corpo da própria mulher, que deveria cuidar-se para melhor cuidar dos filhos.

Nesse sentido, os eixos da representação, dos cuidados com o corpo e da pedagogia da mídia são tentativas de enfrentar teoricamente as realidades construídas a partir dos discursos midiáticos que gradativamente, numa dada configuração histórica, social e cultural, foram definindo, normatizando, idealizando e naturalizando a maternagem com base em processos comunicacionais.

Outra questão importante de enfatizar é que, segundo a revisão mostra, por um lado, há uma ausência ou um tratamento superficial de questões caras ao feminismo como a igualdade e, por outro, uma prevalência do sujeito feminino, dotado de liberdades e responsabilidades individuais. Por um lado, os trabalhos admitem que as representações do feminino naturalizam uma série de elementos forjados no âmbito da cultura. E, por outro, deixam claro que as demandas políticas por igualdade foram, em certa medida, suplantadas por outras, mais debruçadas sobre o sujeito feminino.

Embora não se possa negar a importância da compreensão da mulher como esse indivíduo livre, é preciso levar em consideração que, muitas vezes, esse entendimento permite que a mulher seja responsabilizada por uma série de questões independente das distinções estruturais a que está exposta. Os três eixos, portanto, são marcados por análises que privilegiam a subjetividade feminina.

\section{Mídia e maternidade: perspectivas}

De acordo com o levantamento feito, os estudos estão preocupados, sobretudo, em desnaturalizar ideais de maternidade disseminadas principalmente nos dois últimos séculos, os quais afetam a individualidade da mulher. Há também, de certo, um empenho em fortalecer a figura da mulher enquanto sujeito de direitos, de vontades e de expectativas a serem correspondidos. Com base nesse mapeamento, fica claro que a pesquisa sobre maternidade e mídia ainda é muito recente no Brasil. Ela está bastante vinculada aos estudos de gênero - o que pode ser pensado diante do fato de que o papel de mãe ainda é, em certo sentido, indissociável das identidades femininas. A investigação na direção das questões de maternagem, logo, em muitos casos, é fruto de outras pesquisas debruçadas em larga medida sobre as representações do feminino. Como foi dito, o campo da educação é o que mais se dedica a essa temática, especialmente no Sul do país, onde se concentra a maioria das linhas de pesquisa sobre gênero. 
Se pensarmos no campo da comunicação, os trabalhos sobre mídia e maternidade são bem escassos. Uma breve busca na biblioteca digital da Compós mostra que em nenhum GT (Grupo de Trabalho) do encontro (ativo ou inativo) foram apresentados trabalhos que contivessem no título as palavras "maternidade" ou "mãe(s)" até a finalização deste artigo. Ao pesquisar, no Banco de Teses e Dissertações da Capes, os termos "comunicação" (área de conhecimento) e "maternidade" (todos os campos), foram encontrados quatro trabalhos: as dissertações de mestrado de Mazili (2011) e de Moreira (2011), e as teses de doutorado de Lana (2012) e Guimarães (2011). ${ }^{1}$

Um trabalho que se destaca na área é o da professora do Programa de Pós-Graduação em Comunicação da PUC-RJ, Adriana Braga, Personas materno-eletrônicas. O livro é baseado em sua tese de doutorado defendida em 2007, na Unisinos-RS, e vencedora dos prêmios Capes de Tese (MEC/Brasil) e Harold Innis Award (Media Ecology Association/ EUA). Considerado uma referência no Brasil sobre ecologia da mídia, o trabalho toma a maternidade como condição para as relações estabelecidas no ambiente do blog Mothern (mother + modern), objeto de pesquisa escolhido pela autora (BRAGA, 2008).

Uma questão importante trazida por essa pesquisa é uma mudança que já começa a se perceber na construção social da maternidade. No final do século XIX ela foi marcada pela interferência crescente e gradativa dos médicos, empenhados em dar-lhe um caráter científico. Agora, no início do século XXI, as novas tecnologias se tornam lugares de interação entre as mães, que não abriram mão dos especialistas, mas começam a se incluir nessa categoria, dando conselhos umas às outras, compartilhando suas experiências, questionando não só as antigas figuras de autoridade, mas, em alguns casos, os próprios especialistas.

A edição de outubro de 2013 da revista Pais e Filhos trouxe a seguinte chamada de capa: "Chega de tanto manual para criar os filhos, a especialista no seu bebê é você mesma", e, na edição seguinte, em novembro: "Sem medo de exercer o cargo de mãe. Sim, somos chatas e sabemos o que é melhor para os nossos filhos. Vai encarar?". O saber especialmente das mães é cada vez mais valorizado nas novas mídias.

A página na internet do jornal Folha de $S$. Paulo abriga o blog Maternar, escrito por duas mães. Em $O$ Estado de $S$. Paulo, o blog Crianças em desenvolvimento mostra em seu slogan o lugar compartilhado pelos responsáveis e peritos: "o saber dos pais e o conhecimento dos especialistas". Já o site Bebê.com.br, da editora Abril, hospeda uma gama de blogs escritos por mães, por meio dos quais elas compartilham experiências distintas na tarefa de ser mãe. ${ }^{2}$

1 O banco está passando por uma atualização de dados dos trabalhos depositados. Logo, só oferece produções dos anos de 2011 e 2012, o que limita a busca.

2 "Tudo novo, de novo" - Deborah Trevizan narra as aventuras da chegada do quarto filho; "Quero ser mãe" Malu Martins quer engravidar e, quando o bebê estiver a caminho, dividirá sua alegria conosco; "Mil dicas de mãe" - mãe de primeira viagem divide as experiências que só se aprendem na prática; "Bagagem de mãe" - Loreta compartilha opiniões, dicas, aventuras, desabafos e loucuras de mãe. 
A pesquisa de Braga (2008) problematiza um novo espaço, dentro das novas mídias, de construção da maternidade, onde as mulheres-mães são ouvidas e partilham suas expectativas, frustrações e experiências. O arranjo mãe, mídia e especialistas não deixou de prevalecer, mas parece estar sendo reconfigurado pelas novas mídias e novas possibilidades de interação.

Em se tratando do campo da comunicação, a maternidade também é um espaço interessante para pensar problemáticas relacionadas à sociabilidade, ao consumo e às práticas culturais na mídia, dentre outros. Questões como a relação entre maternidade e cibercultura, conforme exemplificado acima, podem ser bem mais exploradas, levando-se em conta que não apenas os blogs, mas as redes sociais são cada vez mais procuradas como lugar de compartilhamento das práticas de maternagem. Ao inserir no campo de pesquisa do Youtube a frase "como congelar papinha", dezenas de resultados mostram "mães especialistas" ensinando suas técnicas, partilhando suas experiências e oferecendo suas preciosas dicas.

A maternidade é também um lugar extremamente profícuo para pesquisar as questões de poder. Trata-se de ir além do pensamento que aborda a mulher (nesse caso a mulher-mãe) como uma categoria oprimida pelo estado ou em desvantagem diante dos homens, isto é, apenas em termos sexistas. Significa analisar as disputas e negociações crescentes. As mulheres estariam buscando requerer um lugar de saber sobre a maternidade? Se há um empenho em desnaturalizar a condição de mãe, em que bases esses saberes estariam apoiados? A presença crescente de mulheres na apresentação de programas de rádio e TV e edição de revistas e sites especializados na criação de filhos pode ser uma sinalização de que a construção social da maternidade está se voltando para um protagonismo feminino? E quanto aos especialistas, são homens ou mulheres em sua maioria? Tais perguntas remetem a alterações no âmbito da cultura e até mesmo do campo moral.

Não são poucas as críticas sobre as representações do feminino na cultura contemporânea, por meio das quais a mídia é comumente pensada como um lugar de veridição que, por exemplo, exalta um tipo de mulher que só uma pequena parcela pode se tornar, legando a responsabilidade disso apenas ao esforço pessoal (McRobbie, 2006).

Nesse sentido, "as escolhas das mulheres - que devem conduzir ao sucesso - são vistas de maneira individualizada e desconectada da força de poderes institucionais" (LANA, 2012, p. 131). Entretanto, não se pode deixar de pensar que a mídia foi um importante ambiente para que as questões da mulher, restritas ao mundo doméstico, pudessem ser expostas e, nesse sentido, problematizadas, discutidas, desnaturalizadas, repensadas. Ela trouxe a mulher, de certa forma, para o espaço público - com todos os custos que isso pôde acarretar. E, agora, a mídia não estaria possibilitando à mulher-mãe tornar visíveis suas dúvidas e experiências? Isso não possibilitaria que a maternidade fosse um lugar mais nuançado? É possível pensar a construção da maternidade fora das práticas comunicacionais?

Acredito que essas perguntas podem dar continuidade aos estudos baseados na temática maternidade e mídia no Brasil com vistas a seu amadurecimento. Tais questões 
também são capazes de conferir força a essa abordagem especificamente no campo da comunicação, onde as problemáticas que envolvem os gêneros ainda abordam muito superficialmente a maternidade.

Renata Tomaz é doutoranda em Comunicação e Cultura pela Escola de Comunicação da UFRJ, onde concluiu o mestrado (2011) e a graduação em Jornalismo (2004). Possui experiência profissional em jornalismo impresso, eletrônico e digital.

renatactomaz@gmail.com

\section{Referências}

BADINTER, E. Um amor conquistado: o mito do amor materno. Rio de Janeiro: Nova Fronteira, 1985.

BRAGA, A. Personas materno-eletrônicas: feminilidade e interação no blog Mothern. Porto Alegre: Sulina, 2008.

BUTLER, J. Gender trouble. New York: Routledge, 1990.

CADONÁ, E. Amamentar é educar para vida?!?!: a produção da maternidade contemporânea da amamentação. Dissertação (Mestrado em Psicologia). Pontifícia da Universidade Católica, Porto Alegre, 2010.

CHODOROW, N. The reproduction of mothering: psychoanlysis and the sociology of gender. Berkeley, Los Angeles: University of California Press, 1978.

ESCOSTEGUY, A. C. Comunicação e gênero: a aventura da pesquisa. Porto Alegre: EDIPUCRS, 2008.

; BARBOSA, J. A maternidade e a distinção de classe nas narrativas de mulheres da revista Claudia e Zero Hora. Contemporânea, v. 9, n. 3, set.-dez., p. 448-460, 2011.

FISCHER, R. M. B. Mídia e educação da mulher: uma discussão teórica sobre os modos de enunciar o feminino na TV. Estudos feministas, São Carlos, v. 9, n. 2, p. 586-599, 2001.

FOUCAULT, M. História da sexualidade I: a vontade de saber. Rio de Janeiro, Graal, 1988.

Microfísica do poder. Rio de Janeiro, Graal, 1989.

FREIRE, M. M. "Ser mãe é uma ciência": mulheres, médicos e a construção da maternidade científica na década de 1920. História, Ciências, Saúde - Manguinhos, Rio de Janeiro, v. 15, supl., jun., p. 153-171, 2008.

GUIMARÃES, L. Mães cuidam, pais brincam: normas, valores e papéis na publicidade de homenagem. Tese (Doutorado em Comunicação), Universidade Federal de Minas Gerais, Belo Horizonte, 2011.

HALL, S. A identidade cultural na pós-modernidade. Rio de Janeiro: DP\&A, 2006.

LANA, L. C. de C. Personagens públicas na mídia, personagens públicas em nós: experiências contemporâneas nas trajetórias de Gisele Bündchen e Luciana Gimenez. Tese (Doutorado em Comunicação). Universidade Federal de Minas Gerais, Belo Horizonte, 2012. 
MARCELLO, F. de A. Enunciar-se, organizar-se, controlar-se: modos de subjetivação feminina no dispositivo da maternidade. Revista Brasileira de Educação, n. 29, ago., p. 139-151, 2005.

MARTINS, A. P. V. "Vamos criar seu filho": os médicos puericultores e a pedagogia materna no século XX. História, Ciências, Saúde - Manguinhos, Rio de Janeiro, v.15, n.1, jan.-mar., p. 135-154, 2008.

MAZILI, P. A maternidade consumada. Dissertação (Mestrado em Comunicação). Escola Superior de Propaganda e Marketing, São Paulo, 2011.

MEYER, D. Educação, saúde e modos de inscrever uma forma de maternidade nos corpos femininos. Movimento, Porto Alegre, v. 9, n.3, p. 38-52, 2003.

A politização contemporânea da maternidade: construindo um argumento. Gênero, Niterói, v. 6, p. 81-104, 2006.

McROBBIE, A. Pós-feminismo e cultura popular: Bridget Jones e o novo regime de gênero. In: CURRAN, J.; MORLEY, D. Media and Cultural Theory. Tradução: Márcia Rejane Messa. London/ New York: Routlege, 2006, p. 59-69.

MOREIRA, L. G. Em dia com a moda. Da emancipação feminina ao culto à juventude nos anos 60 : a representação da feminilidade nas páginas de A Cigarra. Dissertação (Mestrado em Comunicação). Pontifícia da Universidade Católica, Rio de Janeiro, 2011.

PRADO, Carlos. Vamos criar seu filho!. São Paulo: Guairá, 1938.

REZENDE, C. B. Um estado emotivo: representação da gravidez na mídia. Cadernos Pagu, n. 36, jan.-jun., p. 315-344, 2011.

SCOTT, J. Gênero: uma categoria útil de análise histórica. Educação e realidade, v. 20, n. 2, 1991.

SCAVONE, L. A maternidade e o feminismo: diálogo com as ciências sociais. Cadernos Pagu, Campinas, v. 16, p. 137-150, 2001.

. Dar a vida e cuidar da vida: sobre maternidade e saúde. SCAVONE, L. (ed.). Dar a vida e cuidar da vida: feminismo e ciências sociais. São Paulo: Editora Unesp, 2004a, p. 127-139.

. Maternidade: transformações na família e nas relações de gênero. SCAVONE, L. (ed.). Dar a vida e cuidar da vida: feminismo e ciências sociais. São Paulo: Editora Unesp, 2004b, p. 171-186.

SCHWENGBER, M. S. A Educação da Mãe Carinhosa e o Discurso das Práticas Corporais e Esportiva nas páginas da Pais \& Filhos. Movimento, Porto Alegre, v. 15, p. 209-232, 2009.

A mídia ensina: a criança é soberana. Comunicação, mídia e consumo. São Paulo, v.9, n. 25, set., p. 223-247, 2012.

; MEYER, D. Discursos que (con)formam corpos grávidos: da medicina à Educação Física. Cadernos Pagu, Campinas, v. 36, p. 283-314, 2011.

SILVA, T. T. A produção social da identidade e da diferença. In: Petrópolis: Vozes, 2009, p. 73-102.

(org.). Identidade e diferença.

STEVENS, C. Ressignificando a maternidade: psicanálise e literatura. Revista Gênero, v. 5, n. 2, 2013.

TUTTLE, E. Mother without children: contemporary fiction and the crisis of motherhood. Berkeley: University of California Press, 1997. 